\title{
Aspectos técnicos da produção de pellets de madeira
}

\author{
Technical aspects of wood pellet production
Laurent Roger Marie Quéno ${ }^{I}$, Álvaro Nogueira de Souza ${ }^{I I}$, Alexandre Florian da Costa $^{\mathrm{III}}$, Ailton Teixeira do Vale ${ }^{\mathrm{IV}}$, Maísa Santos Joaquim ${ }^{\mathrm{V}}$

\begin{abstract}
Resumo
A evolução da política energética dos países desenvolvidos, associada à procura por fontes renováveis como a biomassa florestal, impulsionou, desde o início dos anos 2000, o crescimento da produção de pellets de madeira no mundo. O mercado de pellets tornou-se exigente em qualidade e deve lidar com a concorrência de outras fontes de energia, requerendo dos produtores um controle rigoroso de custo bem como um bom domínio técnico da produção. Dessa forma, realizou-se uma revisão bibliográfica sobre os aspectos técnicos da produção de pellets e as possibilidades e as exigências do mercado para que o Brasil possa aproveitar as oportunidades e valorizar o seu potencial florestal.
\end{abstract}

Palavras-chave: Mercado de biomassa; Biocombustíveis; Torrefação

\begin{abstract}
The evolution of the energy policy of developed countries, coupled with the demand for renewable sources such as forest biomass, has boosted the growth of wood pellets throughout the world since the early 2000s. The pellet market has become a demanding quality brand and must deal with competition from other energy sources, requiring producers to a strict control of costs as well as good technical expertise of production. Thus, a literature review was carried out on the technical aspects of pellet production and the possibilities and requirements of the market so that Brazil could seize opportunities and enhance its forest potential.
\end{abstract}

Keywords: Biomass market; Biofuels; Torrefaction

\section{Introdução}

A produção mundial de pellets de madeira tem aumentado nos últimos anos, passando de quantidades insignificantes, no início dos anos 2000, para mais de 28 milhões de toneladas, em 2015 (ORGANIZAÇÃO DAS NAÇÕES UNIDAS PARA ALIMENTAÇÃO E AGRICULTURA, 2017). De um mercado limitado e regional, na Escandinávia e na Áustria, de produtores locais que supriam as necessidades de consumidores em escala individual, o status deste biocombustível sólido mudou e se tornou "commodity", negociada nos mercados internacionais para abastecer usinas termoelétricas das maiores empresas de fornecimento de energia elétrica da Europa (HEINIMO; JUNGINGER, 2009; LAMERS et al., 2012a). Um estudo de prospectiva realizado por Pöyry, (2010) projetou o consumo mundial de pellets, em 2020, de 46 milhões de toneladas por um valor de 8 bilhões de dólares (valores 2010). Em outros estudos, Wihersaari, Agar e Kallio (2009),

Engenheiro Florestal, Dr., Rua N37, Qd40, Lt20, Anápolis City 2ª etapa, CEP 75094-420, Anápolis (GO), Brasil. laurentfloresta@gmail.com (ORCID: 0000-0002-4914-0077)

II Engenheiro Florestal, Dr., Professor do Departamento de Engenharia Florestal, Faculdade de Tecnologia, Universidade de Brasília, CEP 70919-970, Brasília (DF), Brasil. asouza@unb.br (ORCID: 0000-0002-6869-2715)

III Engenheiro Florestal, Dr., Professor do Departamento de Engenharia Florestal, Faculdade de Tecnologia, Universidade de Brasília, CEP 70919-970, Brasília (DF), Brasil. lucate@unb.br (ORCID: 0000-0002-8750-9613)

IV Engenheiro Florestal, Dr., Professor do Departamento de Engenharia Florestal, Faculdade de Tecnologia, Universidade de Brasília, CEP 70919-970, Brasília (DF), Brasil. ailton.vale@gmail.com (ORCID: 0000-0001-5579-2381)

Engenheira Florestal, Dra., Professora da Faculdade de Agronomia e Medicina Veterinária, Universidade de Brasília, CEP 70919-970, Brasília (DF), Brasil. maisaunb@gmail.com (ORCID: 0000-0002-2867-0941) 
Obernberger e Thek (2010) projetaram que, com um crescimento anual de $10 \%$ da demanda mundial de pellets, entre $10 \%$ e $12 \%$ de toda a madeira industrial colhida no mundo será transformada em pellets até o ano de 2025.

\section{O pellet, o biocombustível florestal}

O pellet é um bioco mbustível granulado à base de biomassa vegetal moída e compactada em alta pressão. O calor gerado pela fricção na passagem pelos furos da matriz peletizadora provoca a transformação dos componentes lignocelulósicos. O resultado é um produto adensado de alto poder calorífico e boa resistência mecânica (LI; LIU, 2000; KALIYAN; MOREY, 2009).

Para produzir o pellet, vários tipos de biomassa vegetal são utilizados. Podem ser transformadas matérias de origem agrícola, como as palhas de cereais (NILSONN; BERNESSON; HANSSON, 2011), as palhas lignocelulósicas de gramíneas de alta produtividade dos gêneros Miscanthus (LEHMANN et al., 2012) e Panicum (MANI; TABIL; SOKHANSANJ, 2006), o bagaço da cana-de-açúcar (ALMEIDA; SOLA; BEHAINNE, 2014) e o bambu (LIU et al., 2013). Subprodutos da atividade alimentícia podem ser aproveitados, como, por exemplo, os cachos de dendê (Empty Fruit Bunches, EFB) que, após extração do óleo, são transformados em pellets (RAHMAN et al.,2013)

As operações sucessivas que conduzem ao produto final podem ser inseridas em um fluxograma, como está representado na Figura 1.

Figura 1 - Fluxograma simplificado do processo de peletização.

Figure 1 - Simplified flowchart of the pelleting process.

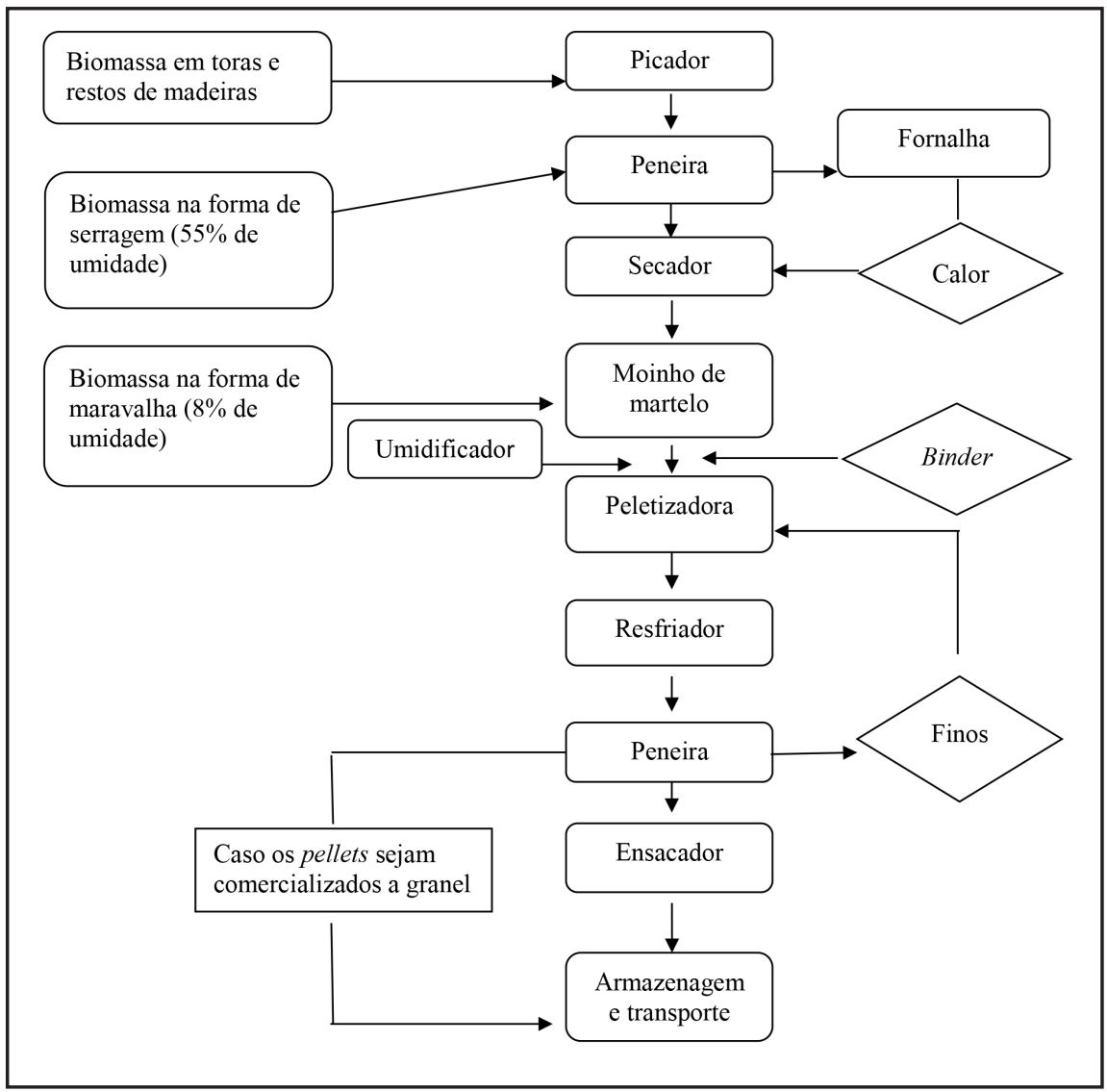

Fonte: Autor (2019) 
Contudo, a principal fonte de matéria-prima para a fabricação de pellets vem da atividade florestal. A transformação em pellets de subprodutos madeireiros e toras de baixo valor comercial produz um biocombustível de excelente qualidade, devido ao baixo teor de cinza (WOLF; VIDLUND; ANDERSSON, 2006).

As diversas matérias-primas florestais utilizadas são (i) os subprodutos da indústria madeireira de segunda transformação, maravalha, serragem e pó da indústria moveleira e de piso; (ii) os subprodutos da indústria madeireira de primeira transformação, serragem, costaneiras e desperdícios das serrarias; (iii) os resíduos da exploração florestal habitualmente não extraídos da floresta, como pontas, galhos e até mesmo tocos e (iv) a biomassa oriunda de plantações dedicadas com curta rotação e alta produtividade.

Depois de recolhidos, triturados e secos, esses materiais são transformados em pó que, posteriormente, é comprimido para obter a forma final. Assim, de 6 a 8 metros cúbicos de serragem ou cavacos de madeira, depois de secos, processados e comprimidos, geram 1 metro cúbico de pellets de madeira. O resultado é um composto $100 \%$ natural de elevado poder calorífico.

Alguns produtores utilizam um agente ligante (binder) de tipo lignossulfonato, amido de milho ou de batata, farelo de canola ou outra matéria vegetal para melhorar o processo de peletização, graças ao efeito de lubrificação dentro do molde, a fim de diminuir o consumo de energia e melhorar a durabilidade dos pellets (AHN et al., 2014). O agente ligante varia em função do tipo de biomassa e da disponibilidade local. Contudo, os lignossulfonatos, que são subprodutos do processo de polpação sulfito da indústria de celulose, são os agentes ligantes mais utilizados pelos produtores de pellets, por terem poder aglomerante que aumenta a resistência mecânica do biocombustível. Em contrapartida, têm efeito negativo no seu valor calorífico e aumentam a emissão de monóxido de carbono. Por isso, as normas limitam o uso desses agentes ao máximo de $2 \%$ da massa total do produto (TARASOV; SHAHI; LEITCH, 2013).

\section{Fatores favoráveis à expansão mundial do pellet}

\section{Uma energia com um saldo carbono favorável}

O fator principal que desencadeou a expansão do consumo mundial de pellet foi a necessidade de reduzir a utilização de energias fósseis que apresentam vários problemas, entre eles a poluição com gases de efeito estufa (GEE), que provocam mudanças climáticas irreversíveis, prejudicando as condições de vida das gerações futuras (THE INTERGOVERNMENTAL PANEL ON CLIMATE CHANGE, 2014).O protocolo de Quioto, ratificado em 15 de março de 1999, pela maioria dos países do mundo, menos os Estados Unidos, foi o início de uma transição energética em direção a uma matriz mais sustentável, incluindo a utilização da biomassa e, especialmente, o pellet de madeira (MOISEYEV et al., 2011; ABT et al., 2014). Nos dias 23 e 24 de outubro de 2014, durante o Conselho Europeu reunido em Bruxelas (Bélgica), os dirigentes dos países europeus adotaram o "Quadro energia-clima 2030", que comporta três objetivos que são: reduzir em $40 \%$ as emissões de GEE em relação ao ano de 1990, colocar as energias renováveis no patamar de $27 \%$ do consumo da energia da União Europeia e melhorar a eficiência energética em 30\%.

Alguns estudos foram realizados para avaliar o quanto o uso de pellets na produção de energia permite a realização de uma economia de emissão de GEE. Segundo Pinel (2013), a quantidade de $\mathrm{CO}^{2}$ emitido ao longo da cadeia que abrange a produção, o transporte e a combustão, por kWh produzido, é até seis vezes inferior à de óleo combustível, no caso do aquecimento residencial, passando de 280 a $34 \mathrm{gCO}^{2}$ eq por $\mathrm{kWh}$ gerado. $\mathrm{Na}$ mesma ordem, o balanço energético global da cadeia do pellet industrial vindo das províncias do oeste canadense, incluindo a produção e o transporte até a usina termoelétrica europeia, mostra um saldo positivo, comparado à produção de eletricidade a partir de carvão (DAMEN; FAIJ, 2003). 


\section{A competitividade e a baixa volatilidade dos preços do pellet}

O aumento significativo da demanda por pellets não seria possível se o biocombustível não fosse competitivo em relação às outras formas de energia disponíveis no mercado. Por exemplo, foi estimada a economia realizada na calefação de uma casa no Canadá, se fossem utilizados pellets de madeira em vez das energias tradicionais. Para o óleo de petróleo, a economia seria de 55\%; para o gás propano, de 46\% e para a energia elétrica, 23\% (RESOMASS, 2013).

Além disso, a evolução do preço dos pellets demonstra uma grande estabilidade ao longo desses últimos anos. A taxa de crescimento anual médio do preço dos pellets foi estimada, entre 2010 e 2015, em 3,7\%, na França e em 2,6\%, na Bélgica, enquanto, para o gás, foi de 5\%, para o gás propano líquido 4,6\% e para o óleo combustível, 6,9\% (PINEL, 2013; ASSOCIATION POUR LES ENERGIES RENOUVELABLES, 2015).

A baixa volatilidade dos preços dos pellets e da biomassa de origem florestal em geral, comparada à das energias fosseis, foi alvo de estudos. Kranzl et al. (2009) demonstraram que os preços das commodities de bioenergia são menos voláteis do que os dos combustíveis fósseis e contribuem, assim, para uma maior segurança no custo da energia em longo prazo, por um país utilizando uma matriz energética diversificada.

\section{As características técnicas e térmicas dos pellets}

A qualidade dos pellets permite utilizá-los como qualquer combustível. O biocombustível sólido tem baixo teor de umidade (8\%), associada a um alto poder calorífico, cerca de $17 \mathrm{MJ} \mathrm{kg}^{-1}$. Sua densidade a granel é superior a $600 \mathrm{~kg} / \mathrm{m}^{3}$, enquanto a do cavaco é de 220 a $250 \mathrm{~kg} / \mathrm{m}$, com teor de umidade que oscila entre $40 \%$ e $50 \%$. Consequentemente, a densidade energética dos pellets fica mais que cinco vezes maior que a do cavaco, passando de $0,6 \mathrm{MWh} / \mathrm{m}^{3}$ para $3,12 \mathrm{MWh} / \mathrm{m}^{3}$.

Seu manuseio é relativamente fácil, graças à sua boa fluidez e boa resistência aos choques. O conjunto desses fatores facilita seu transporte, seja em pequenas quantidades, seja a granel, por caminhão ou navio, sem que seu equilíbrio energético seja afetado. Seu armazenamento pode ocorrer por longos períodos, sem perda de matéria seca e sem alteração significativa de sua eficiência térmica (WU; SCHOTT; LODEWIJKS, 2011).

Outra vantagem dos pellets, comparados a outros biocombustíveis sólidos, é a ausência de risco fitossanitário que pode ocorrer com cavacos e outros subprodutos madeireiros, que são vetores de propagação de insetos perigosos para as florestas, especialmente nematódeos do pinheiro (LAMERS et al., 2012b). Esse aspecto é importante para a Europa, que impôs restrições sanitárias à importação dessa biomassa, especialmente da América do Norte.

Por ser menos industrializado, o cavaco fica mais competitivo e eficiente energeticamente quando não há uma grande distância entre a fonte de produção da biomassa e o consumidor industrial. O uso do cavaco requer um espaço de estocagem suficiente para permitir-lhe perder sua umidade, a fim de aumentar seu poder energético e evitar sua degradação por agentes biológicos (GEJDOS et al., 2015). Caso contrário, o cavaco será sujeito à fermentação com aumento da temperatura, crescimento de colônias de fungos e produção de grandes quantidades de esporos, com risco tanto para a saúde das pessoas encarregadas do manuseio como de autocombustão da biomassa (SUCHOMEL et al., 2014).

\section{O aperfeiçoamento tecnológico}

A tecnologia de produção de pellets se aperfeiçoou, permitindo o aproveitamento de vários tipos da biomassa florestal. A produtividade das fábricas aumentou, gerando menor custo de produção em escala, tornando-se competitiva frente às outras fontes de energia (TROMBORG et al., 2013). 
Os sistemas de combustão, tanto residenciais como coletivas ou industriais, melhoraram permitindo alta eficiência energética, superior a $90 \%$, com uma gestão mais flexível no dia a dia e com produção limitada de cinzas e poluentes (HANSON, 2014). O uso desses fogões e caldeiras com alimentação automática e ajustada de pellets e de ar durante a combustão permite abaixar a emissão de partículas finas (PM) e de poluentes, como o monóxido de carbono (CO), os óxidos de nitrogênio (NOx) e os compostos orgânicos gasosos ( $\mathrm{CxHy}$ ), comparados aos tradicionais fogões à lenha (KISTLER et al., 2012).

\section{Exigências do mercado internacional}

\section{As garantias de qualidade}

Vários países desenvolveram normas nacionais para garantir ao consumidor um padrão de qualidade e de segurança no uso de pellets para o aquecimento residencial, como, por exemplo, a Suécia (SS 187.1200) e a Áustria (ÖNORM M 7135), desde 1990, e a Alemanha (DIN 51731), desde 1996. São países que já têm importante e tradicional cadeia industrial madeireira que valoriza a produção florestal nacional e que começaram a produzir pellets para atender às necessidades energéticas dos mercados locais. Com o crescimento do comércio internacional, surgiu a necessidade de uma norma unificada para o nível europeu que seja aceita por todos os atores da cadeia da produção e do comércio de todos os países europeus.

Deve-se distinguir a norma EN 14961, que define um conjunto de exigências de qualidade dos pellets, e o sistema de certificação ENplus, que é um selo que garante que todo o processo de produção respeita controles de qualidade predefinidos (PELLET ATLAS, 2009).

A norma EN 14961 é composta de seis partes. A primeira parte, EN 14961-1, fornece a estrutura para um método comum e claro de classificação para os biocombustíveis sólidos. O objetivo é criar uma linguagem comum para fornecedores de biomassa, fábricas, clientes e também, por exemplo, fabricantes de equipamentos. As outras cinco partes são normas de produto para as formas comumente negociadas de biocombustíveis sólidos, tais como pellets de madeira (EN 14961-2), briquetes (EN 14961-3), cavacos (EN 14961-4), lenhas (EN 14961-5) e agropellets (EN 14961-6).

Devem-se distinguir duas normas europeias para o pellet de madeira que são: uma norma mais exigente para o uso doméstico não industrial para as instalações de aquecimento e de energia de até $1 \mathrm{MW}$ em edifícios privados, comerciais e públicos, e outra para o uso em plantas energéticas de grande porte. Desde então, todas as normas nacionais devem se alinhar no nível de exigência da norma europeia. Por exemplo, a norma francesa para pellets de uso doméstico foi adaptada e tornou-se NF-EN 14961-2, com três níveis de exigência.

Os valores medidos e definidos pelas normas são, geralmente, aqueles diretamente ligados à qualidade da combustão dos pellets. São regulamentados os pontos seguintes (ALAKANGAS, 2009; 2010): dimensões, diâmetro e comprimento (mm); teor de umidade (\%); teor de cinzas (\%); resistência mecânica do pellet à compressão e ao choque (\% da massa); teor de finos (\% da massa); poder calorífico inferior (PCI), expresso em megajoule por quilograma $(\mathrm{MJ} / \mathrm{kg})$ ou por $\mathrm{kWh}$ por tonelada $(\mathrm{kWh} / \mathrm{t})$; massa volúmica aparente ou densidade a granel $\left(\mathrm{kg} / \mathrm{m}^{3}\right)$; teores de enxofre $(\mathrm{S})$, cloro $(\mathrm{Cl})$ e nitrogênio $(\mathrm{N})\left(\%\right.$ do produto seco); temperatura de deformação das cinzas $\left(\mathrm{C}^{\circ}\right)$ e, opcionalmente, os teores de metais pesados, arsênico $(\mathrm{As})$, cobre $(\mathrm{Cu})$, cromo $(\mathrm{Cr})$, cádmio $(\mathrm{Cd})$, mercúrio $(\mathrm{Hg})$, níquel $(\mathrm{Ni})$, chumbo $(\mathrm{Pb})$ e zinco $(\mathrm{Zn})(\mathrm{mg} / \mathrm{kg})$.

ENplus é uma marca que garante a qualidade em toda a cadeia de fornecimento. Os pellets só podem ser vendidos com a marca ENplus quando cada agente da cadeia de fornecimento (produtores, comerciantes e varejistas) é certificado individualmente. Além disso, ela abrange não somente as questões de qualidade, mas também critérios de sustentabilidade e segurança de abastecimento, que são cruciais para o desenvolvimento futuro do mercado de pellet (EUROPEAN PELLET COUNCIL, 2013). Segundo Rakos (2015), os pellets certificados ENplus representam 65\% do mercado europeu. $\mathrm{Na}$ 
Alemanha e na Áustria, o mercado mais exigente, essa porcentagem atinge 90\%.

\section{As exigências socioambientais}

Além das normas de qualidade, foram estabelecidas exigências socioambientais. O desenvolvimento desorganizado das bioenergias em âmbito mundial pode provocar uma competição para o uso de terras agrícolas (LUPP et al., 2015; MALTSOGLOU et al., 2015), especialmente aquelas que são tradicionalmente utilizadas pelas comunidades rurais pobres (BAILEY, 2008). Outra consequência pode ser a transformação de ecossistemas de alto valor ecológico ou, ainda, ter um balanço limitado ou, mesmo, negativo na redução dos gases de efeito estufa (GEE) (RÖDER; WHITTAKER; THORNLEY, 2015).

O fato de que os biocombustíveis derivados de madeira não entram em competição com a demanda alimentar mundial é uma grande vantagem. Mas há, potencialmente, outros problemas socioambientais que as instâncias governamentais dos países importadores querem evitar e por isso colocaram uma série de exigências que envolvem três níveis de garantias que são: (i) o balanço dos gases de efeito estufa (GEE); (ii) a garantia da produção florestal respeitando critérios estritos de sustentabilidade e (iii) a proteção das populações rurais que habitam o local em que é explorado o biocombustível (GOH; JUNGINGER, 2013).

Na Europa, deve citar-se a associação de compradores institucionais de biomassa florestal, chamada "Initiative Wood Pellets Buyers (IWPB)", que reúne as principais indústrias de grande porte na geração de energia, tais como as empresas alemãs EON e RWE; a britânica DRAX; a firma dinamarquesa DONG; a francesa GDF-SUEZ, por meio de seu laboratório de R\&D LABORELEC e a estatal sueca VATTENFALL, que adotaram uma série de princípios de sustentabilidade que devem reger o mercado de importação de biocombustíveis sólidos (RYCKMANS, 2011).

\section{Evoluções do mercado}

\section{Competição do pellet e da biomassa florestal com outros usos da madeira}

O custo de produção do pellet é normalmente baixo porque é baseado no reaproveitamento de uma matéria-prima barata, feita de subprodutos que antes eram abandonados por serrarias e outras indústrias madeireiras. Mas, com o aumento contínuo dessa demanda, vê-se, hoje, em vários países, a dificuldade para encontrar matéria-prima suficiente para abastecer o mercado. Surge, então, a questão para utilizar outras fontes de matéria-prima, com custo mais elevado, o que afetará o preço final do pellet ao consumidor (TROMBORG et al., 2013).

$\mathrm{O}$ crescimento atual da produção mundial de pellets será possível não apenas utilizando-se os subprodutos da indústria madeireira. Será necessário colher madeira diretamente em floresta para essa finalidade. No imenso maciço florestal do sudeste dos Estados Unidos, composto principalmente de plantações de Pinus taeda, várias fábricas de grande porte com produção anual superior a 100.000 toneladas foram instaladas nesses últimos anos (MANDELL; LANG, 2013).

Moiseyev et al. (2011) analisaram o risco de competição entre as necessidades de abastecimento das indústrias de painéis de madeira (compensado, OSB e MDF) e de celulose, frente a uma demanda crescente da biomassa florestal para fins energéticos. Essas indústrias estavam acostumadas a comprar uma matéria-prima de baixo custo, geralmente subprodutos da indústria de serragem, ou diretamente das florestas, como pequenas árvores provindas dos desbastes das plantações de coníferas ou de corte de talhadias de folhosas, com pouca utilidade para usos nobres. O aumento da demanda de madeira para energia representa uma ameaça para essas indústrias, cujo custo de abastecimento aumentará. 


\section{Possibilidades de evoluções futuras}

Uma das evoluções no método de produção de pellets é a torrefação (PIRRAGLIA et al., 2012). A torrefação é um processo termoquímico lento que dura de 30 a 90 minutos, em atmosfera inerte e temperatura variando entre $200^{\circ} \mathrm{C}$ e $300^{\circ} \mathrm{C}$. Ela provoca a volatilização da hemicelulose e, assim, muda as propriedades da biomassa, tornando-a hidrofóbica e mais leve porque toda a umidade se evapora, o que é importante para o transporte (WIHERSAARI; AGAR; KALLIO, 2009). A fração incluindo as matérias voláteis e a hemicelulose é queimada para gerar o calor necessário durante o processo de torrefação. A madeira torrificada é constituída da fração restante composta de celulose e lignina. Dependendo do tempo de permanência no torrefator, o rendimento de madeira torrificada pode ser alto, variando de $66 \%$ até $75 \%$ (ZWART; BOERRIGER; VAN DER DRIFT, 2006; SKLAR, 2009).

Assim, sendo o pellet de biomassa torrificada mais denso energeticamente, 1,3 vezes segundo Sklar (2009), o custo de transporte da sua unidade energética diminui. Isso é importante visto que a competitividade do pellet é sensível ao custo do transporte. Por exemplo, no caso do Canadá, o custo (em dados de 2004) do conjunto, englobando o transporte local, o armazenamento e a expedição por cargo até o porto de Rotterdam, é de $3,2 € \mathrm{GJ}^{-1}$, enquanto o preço dos pellets pago ao produtor foi de $5,4 € \mathrm{GJ}^{-1}$ (JUNGINGER et al., 2008).

Além de uma maior densidade energética, próxima à do carvão mineral, 20-23 GJ por tonelada, a torrefação produz um pellet hidrofóbico com maior densidade a granel e com nenhum risco de degradação biológica. Os pellets de madeira torrificada apresentam qualidades técnicas idênticas às do carvão no processo de trituração/pulverização, o que faz dele um substituto ideal na cocombustão em termoelétrica. Por isso, a produção de pellets de madeira torrificada é objeto de pesquisas e de investimentos importantes, na esperança de misturá-los ao carvão na produção de energia elétrica (PIRRAGLIA et al., 2013). Outra aplicação promissora foi identificada na possibilidade de utilizá-los com êxito no processo de gaseificação em plantas com alimentação à base de biomassa seca em leito fluidizado (DEUTMAYER, 2011).

A torrefação pode ser realizada antes ou depois da peletização da biomassa (GHIASI et al., 2014; MOBINI et al., 2014). Quando a torrefação é realizada antes da peletização, a biomassa resultante, que perdeu água e grande proporção dos seus produtos voláteis, torna-se seca, quebradiça e com cor mais escura. A biomassa assim torrificada é mais fácil para moer, o que reduz em até $70 \%$ a $90 \%$ o consumo de energia, durante essa fase no processo de peletização (SHANG et al., 2012).

É urgente a necessidade da realização de pesquisas técnicas sobre torrefação e peletização da madeira das diferentes espécies e clones de eucalipto cultivados no Brasil, como foi realizado nos Estados Unidos sobre Eucalyptus benthamii e Eucalyptus macarthurii, por Pirraglia et al. (2012). O Brasil é um grande produtor de eucalipto para fins energéticos (ASSOCIAÇÃO DE PRODUTORES DE FLORESTAS PLANTADAS, 2012). Algumas dificuldades se apresentam na peletização da madeira de eucalipto e que podem ser contornadas pela torrefação.

A peletização da madeira de eucalipto é mais difícil que a das coníferas, pelo fato de apresentar teor mais baixo de extrativos. Nielsen, Gardner e Felby (2010) demonstraram que os extrativos atuam como lubrificantes e "plastificantes" que diminuem a necessidade de energia durante o processo de peletização. Assim, para a peletização do eucalipto, a matriz peletizadora deve ser adaptada e com a necessária adição de um agente ligante (binder) que age como lubrificante e evita um consumo excessivo de energia. Deve-se também cuidar do teor de cinza que pode ser alto $( \pm 1 \%)$ em algumas condições, especialmente quando a madeira é colhida precocemente (SOARES et al., 2014).

No Brasil, considerando a possibilidade de exportar para os países consumidores europeus, é manifeste que os plantios potenciais de eucalipto estão distantes dos principais portos marítimos. Dessa forma, a inclusão da torrefação no processo de peletização pode ajudar a reduzir o custo de transporte, além baixar o custo energético de produção do pellet. Assim, a 
torrefação permitiria produzir um pellet industrial diferenciado, com maior valor agregado e mais competitivo no mercado internacional dos biocombustíveis sólidos (WILD et al., 2016).

\section{Considerações finais: a situação no Brasil}

Garcia (2010) analisou os pellets fabricados por quatro indústrias e demonstrou que os padrões não foram atingidos, especialmente no poder calorífico e na durabilidade mecânica. Mas, Quéno (2015), levantando a situação de nove empresas produtoras de pellets à base de maravalha de pinus nos três estados do sul do Brasil, encontrou oito delas com controle de qualidade interno estabelecido, três com o selo de qualidade ENplus e duas em fase de certificação. Isso mostra o "upgrade", em pouco tempo, na qualidade das produtoras brasileiras, no desejo de atender ao mercado externo promissor.

Uma iniciativa privada, com o apoio de dois laboratórios universitários, em Lages, no Brasil e em Ancona, na Itália, está trabalhando para a introdução de um selo de qualidade BRplus, para a padronização da produção e da comercialização de pellets (QUÉNO, 2015). A exemplo da Nova Zelândia (HENNESSY, 2010), o Brasil poderia se apoiar no trabalho importante realizado pelo Comitê Europeu de Normatização (CEN), que fez um extenso trabalho de especificações técnicas na última década. Como a Europa é o maior mercado consumidor e importador de pellets do mundo, é natural a tendência de que as suas normas vigentes se tornem padrões a serem exigidos para os outros países exportadores interessados em vender suas produções.

Nas estatísticas da FAO, o Brasil aparece na $35^{\text {a }}$ colocação do ranking dos países produtores de pellets, mas, por outro lado, é um dos maiores produtores mundiais de madeira serrada. Segundo Quéno (2015), a produção brasileira de pellets é essencialmente baseada na transformação da maravalha de madeira de pinus, resultando, potencialmente, em um pellet de boa qualidade, que pode facilmente obter a certificação europeia Premium ENplus. Segundo Garcia et al. (2016), são 13 fábricas em produção no Brasil, essencialmente no sul do país.

A produção brasileira de pellets cresceu rapidamente esses últimos anos, passando de 57.000 toneladas em 2012, para 470.000 toneladas em 2017 (FAO, 2019). Segundo a FAO, o Brasil exportou 108.376 toneladas de pellets em 2017, ou seja, 23\% de sua produção. O maior mercado para o Brasil é a Itália, para onde foram realizadas a quase totalidade de suas exportações em 2016, segundo dados fornecidos pelo Serviço Nacional de Informações Florestais (SERVIÇO NACIONAL DE INFORMAÇÕES FLORESTAIS, 2019).

A transformação em pellet dos resíduos de madeiras coníferas é mais fácil e acessível, tecnologicamente. No Brasil, são 1,6 milhão de hectares plantados de pinus. As indústrias madeireiras que não são do ramo da produção de celulose e papel e de painéis reconstituídos consomem, anualmente, aproximadamente 27,5 milhões de $\mathrm{m}^{3}$ de madeira de pinus em tora (ASSOCIAÇÃO DE PRODUTORES DE FLORESTAS PLANTADAS, 2013; SERVIÇO NACIONAL DE INFORMAÇÕES FLORESTAIS, 2015), o que poderia representar 1,6 milhão de toneladas de pellets de qualidade Premium ENplus, produzidos somente a partir dos resíduos (QUÉNO, 2015).

O Brasil apresenta grande potencial parcialmente aproveitado na produção de pellets a partir de resíduos das indústrias madeiras à base de pinus. Além disso, o país pode desenvolver uma produção em grande escala, baseada em plantações de eucalipto dedicadas, como foi realizado com sucesso, tanto para a produção de celulose quanto para a de carvão vegetal. Para alcançar esse objetivo, um esforço específico de pesquisa deve ser realizado.

\section{Referências}

ABT, K. L. et al. Effect of policies on pellet production and forests in the U.S. South: a technical document supporting the forest service update of the 2010 RPA Assessment. [s. 1.]: USDA forest Service, 2014. 20 p. 
AHN, B. J. et al. Effect of binders on the durability of wood pellets fabricated from Larix kaemferi C. and Liriodendron tulipifera L. sawdust. Renewable Energy, Amsterdam, v. 62, p. 18-23, 2014.

ALAKANGAS, E. European standards for solid biofuels. Fuel specification and classes, multipart standard Case - wood pellets \& chips. VTT. Convenor of the CEN/TC 335 WorkingGroup2. [s. 1.: s. n.], 2009.

ALAKANGAS, E. New European Pellet Standard. EN 14961-1. EUBIONET. 2010. Disponível em: $<$ http://www.infobio.ru/sites/default/files/Alakangas_Pellet_standard_EN14961-1.pdf> Acesso em: 18 fev. 2018

ALMEIDA, L. F. P.; SOLA, A. V. H.; BEHAINNE, J. J. R. Análise físico-química do produto e processo de peletização da biomassa bagaço de cana-de-açúcar. In: CONGRESSO BRASILEIRO DE ENGENHARIA DE PRODUÇÃO, 4., 2014, Ponta Grossa. Anais... Ponta Grossa: [s. n.], 2014.

ASSOCIAÇÃO DE PRODUTORES DE FLORESTAS PLANTADAS. Anuário estatístico ABRAF 2013. Ano base 2012. ABRAF: Brasília, 2013.148 p.

ASSOCIATION POUR LES ENERGIES RENOUVELABLES. Observatoire des prix de l'énergie. Bruxelas: APERe, 2015. Disponível em: <http://www.apere.org/observatoire-des-prix>. Acesso em: 17 jul. 2017.

BAILEY, R. Another inconvenient truth: how biofuel policies are deepening poverty and accelerating climate change. Oxfam Policy Practice Climate Change Resilience, [s. 1.], v. 4, n. 2, p. $1-58,2008$.

DAMEN, K.; FAAIJ, A. A life cycle inventory of existing biomass import chains for "green" electricity production. Utrecht: Copernicus Institute; Utrecht University, 2003.

DEUTMEYER, M. Refining the quality of pellets: the promise of torrefaction. In: GLOBAL Wood Pellet Industry Market And Trade Study. [s. 1.]: IEA Bioenergy, 2011. 190 p.

EUROPEAN PELLET COUNCIL. Handbook for Certification of Wood Pellets for Heating Purposes. Version 2.0. [s. 1.: s. n.], 2013. 46 p.

GARCIA, D.P. Caracterização química, física e térmica de pellets de madeira produzidos no Brasil. Dissertação de Mestrado em Engenharia Mecânica. Universidade Estadual Paulista, faculdade de Engenharia de Guaratinguetá, 2010. 103 p.

GARCIA, D. P. et al. Trends and challenges of brazilian pellets industry originated from agroforestry. Cerne, Lavras, v. 22, n. 3, jul./set. 2016.

GEJDOS, M. et al. Wood chips storage \& energy. BioResources, Raleigh, v. 10, n. 3, p. 5544-5553, 2015.

GOH, C. S.; JUNGINGER, M. Sustainable Biomass and bioenergy in the Netherlands: Report 2013. Utrech: Copernicus Institute; Utrecht University, 2013. 87 p.

GHIASI, B. et al. Densified biocoal from woodchips: Is it better to do torrefaction before or after densification? Applied Energy, Amsterdam, v. 134, n. 1, p. 133-142, 2014.

HANSON, C. The advance of the austrian pellet boilers. Biomass Magazine, Grand Forks, 25 jun., 2014.

HEINIMÖ, J.; JUNGINGER, M. Production and trading of biomass for energy - An overview of the global status. Biomass \& Bioenergy, Amsterdam, v. 33, n. 9, p. 1310-1320, 2009.

HENESSY, W. Review of wood fuel testing standards. [s. 1.]: EECA; CRL Energy, 2010. 33 p. Disponível em: <http://www.eeca.govt.nz/resource/review-wood-fuel-testing-standards $>$. Acesso em: 29 jul. 2015. 
JUNGINGER, M. et al. Developments in international bioenergy trade. Biomass \& Bioenergy, Amsterdam, v. 32, p. 717-729, 2008.

KALIYAN, N.; MOREY, V. Factors affecting strength and durability of densified biomass products. Biomass \& Bioenergy, Amsterdam, v. 33, p. 337-359, 2009.

KISLER, M. et al. Odour, gaseous and PM10 emissions from small scale combustion of wood types indigenous to Central Europe. Atmospheric Environment, Amsterdam, v. 51, p. 86-93, 2012.

KRANZL, L. et al. Does bioenergy contribute to more stable energy prices? In: IAEE EUROPEAN CONFERENCE ON ENERGY, POLICIES AND TECHNOLOGIES FOR SUSTAINABLE ECONOMICS, 10. Proceedings... [s. 1.: s. n.], 2009. p. 7-10.

LAMERS, P. et al. Global wood chip trade for energy. IEA Bioenergy Task 40 Sustainable International Bioenergy Trade. [s. 1.: s. n.], 2012a. 20 p.

LAMERS, P. et al. Developments in international solid biofuel trade - An analysis of volumes, policies, and market factors. Renewable and Sustainable Energy Reviews, Amsterdam, v. 16, p. 3176-3199, 2012b.

LEHMANN, B. et al. Effect of Miscanthus addition and different grinding processes on the quality of wood pellets. Biomass \& Bioenergy, Amsterdam, v. 44, p. 150-159, 2012.

LI, Y.; LIU, H. High-pressure densification of wood residues to form an upgraded fuel. Biomass \& Bioenergy, Amsterdam, v. 19, p. 177-186, 2000.

LIU, Z. et al. Of carbonization conditions on properties of bamboo pellets. Renewable Energy, Amsterdam, v. 51, p. 1-6, 2013.

LUPP, G. et al. Impacts of increasing bioenergy use on ecosystem services on nature and society exemplified in the German district of Görlitz. Biomass \& Bioenergy, Amsterdam, v. 83, p. 131$140,2015$.

MALTSOGLOU, I. et al. Combining bioenergy and food security: an approach and rapid appraisal to guide bioenergy policy formulation. Biomass \& Bioenergy, Amsterdam, v. 79, p. 80-95, 2015.

MANDELL, B.; LANG, A. H. Update and Context for U.S. wood bioenergy markets. [s. 1.]: Forisk Consulting, 2013. 15 p. Disponível em: <http://www.theusipa.org/Documents/NAFO-US_ Bioenergy_Markets-FINAL-201306261.PDF>. Acesso em: 05 out. 2015.

MANI, S.; TABIL, L. G.; SOKHANSANJ, S. Effects of compressive force, particle size and moisture content on mechanical properties of biomass pellets from grasses. Biomass $\&$ Bioenergy, Amsterdam, v. 30, p. 648-654, 2006.

MOBINI, M. et al. Assessing the integration of torrefaction into wood pellet production. Journal of Cleaner Production, Amsterdam, v. 78, p. 216-225, 2014.

MOISEYEV, A. et al. An economic analysis of the potential contribution of forest biomass to the EU RES target and its implications for the EU forest industries. Journal of Forest Economics, Umeå, v. 17, p. 197-213, 2011.

NIELSEN, N.P. K.; GARDNER, D. J.; FELBY, C. Effect of extractives and storage on the pelletizing process of sawdust. Fuel, Amsterdam, v. 89, p. 94-98, 2010

NILSSON, D.; BERNESSON, S.; HANSSON, P. Pellet production from agricultural raw materials: a systems study. Biomass \& Bioenergy, Amsterdam, v. 35, p. 679-689, 2011.

OBERNBERGER, I.; THEK, G. The pellet handbook: the production and thermal utilization of pellets. London:Earth Scan, 2010. 600 p.

\section{ORGANIZAÇÃO DAS NAÇÕES UNIDAS PARA ALIMENTAÇÃO E AGRICULTURA.}


Statistics Division Forestry Production and Trade. Roma: FAO, [2019]. Disponível em: <http:/ www.fao.org/faostat/en/\#data/FO>. Acesso em: 11 set. 2019.

PELLET ATLAS. Advancement of pellets-related European standards.Munich:WIP Renewable Energies, 2009. 26 p. Disponível em: <http://ec.europa.eu/energy/intelligent/projects/sites/ieeprojects/files/projects/documents/pelletslas_pellet_standards.pdf $>$. Acesso em: 11 jul. 2017.

PINEL, J. La filière pellets en France : une filière à structurer dans un contexte d'internationalisation rapide du marché. Paris: E-CUBE strategy consultants, 2013.12 p.

PIRRAGLIA, A. et al. Fuel properties and suitability of Eucalyptus Benthamii and Eucalyptus Macarthurii for torrefied wood and pellets. BioResources, Raleigh, v. 7, n. 1, p. 217-235, 2012.

PIRRAGLIA, A. et al. Technical and economic assessment for the production of torrefiedlignocellulosic biomass pellets in the US. Energy Conversion and Management, Amsterdam, v. 66, p. 153-164, 2013.

PÖYRY. Pöyry view point, Global market, players and trade to 2020. London: Pöyry, 2010. Disponível em: <http://www.poyry.co.uk/sites/www.poyry.co.uk/files/110.pdf>. Acesso em: 29 jul. 2015

QUÉNO, L. R. M. Produção de pellets de madeira no Brasil: estratégia, custo e risco do investimento. 2015. 152 f. Tese (Doutorado em Ciências Florestais) - Universidade de Brasília, Brasília, 2015.

RAHMAN, A. et al. Study on the potential of pelletisation of empty fruit bunch with sago as binding agent for power generation. European International Journal of Science and Technology, [s. 1.], v. 2, n. 2, 2013.

RAKOS, C. Argus questions and answers: European Pellet Council. Argus Biomass Markets, Weekly Biomass Market News and Analysis, London, n. 15-002, 2015.

RESOMASS. La nouvelle logique energétique. 2013. Disponível em: <http://www.resomass.com/ fr/>.Acesso em: 22 mar. 2015.

RÖDER, M.; WHITTAKER, C.; THORNLEY, P. How certain are greenhouse gas reductions from bioenergy? Life cycle assessment and uncertainty analysis of wood pellet-to-electricity supply chains from forest residues. Biomass \& Bioenergy, Amsterdam, v. 79, p. 50-63, 2015.

RYCKMANS, Y. Sustainability principles as proposed by Initiative Wood Pellets Buyers. [s. 1.]: Biomass and Waste Competence Centre, 2011. Disponível em: $<$ http://www.laborelec.be/ENG/ wp-content/uploads/PDF/2011-03-16-WG_Sustainability-Yves_Ryckmans.pdf>. Acesso em: 11 jul. 2017.

SERVIÇO NACIONAL DE INFORMAÇÕES FLORESTAIS. Produção florestal. Brasília: SNIF, 2015. Disponível em: <http://snif.florestal.gov.br/pt-br/estatisticas-florestais >. Acesso em: 11 set. 2019.

SHANG, L. et al. Quality effects caused by torrefaction of pellets made from Scots pine. Fuel Processing Technology, Amsterdam, v. 101, p. 23-28, 2012.

SKLAR, T. Torrefied wood, a bio-energy option that is ready to go": a biomass digest special report. [s. 1.: s. n.], 2009. Disponível em: <http://biomassdigest.net/blog/2009/12/31/torrefiedwood-a-bio-energy-option-that-is-ready-to-go-a-biomass-digest-special-report/>. Acesso em: 14 nov. 2015

SOARES, V. S. et al. Correlações entre as propriedades da madeira e do carvão vegetal de híbridos de eucalipto. Revista Árvore, Viçosa, MG, v. 38, n. 3, p. 543-549, 2014.

SUCHOMEL, J. et al. Fungal spores in chips. BioResources, Raleigh, v. 9, n. 3, p. 4410-4420, 2014. 
TARASOV, D.; SHAHI, C.; LEITCH, M. Effect of additives on wood pellet physical and thermal characteristics: a review. International Scholarly Research Notices Forestry, London, v. 2013, ID 876939, 6 p.

THE INTERGOVERNMENTAL PANEL ON CLIMATE CHANGE. Climate change 2014: synthesis report. Contribution of working groups I, II and III to the fifth assessment report of the Intergovernmental Panel on Climate Change. Geneva: IPCC, 2014. 151 p.

TRØMBORG, E. et al. Economic sustainability for wood pellets production: a comparative study between Finland, Germany, Norway, Sweden and the US. Biomass \& Bioenergy, Amsterdam, v. 57, p. 68-77, 2013.

WIHERSAARI, M.; AGAR, D.; KALLIO, M. Scenario analysis of fuel-pellet production: the influence of torrefaction on material flows and energy balances. Uppsala: University of Jyväskylä, 2009. Disponível em: <http://www.innovawood.com/Portals/0/documents/Margareta\%20 Wihersaari.pdf $>$. Acesso em: 04 out. 2015.

WILD, M. et al. Possible effects of torrefaction on biomass trade. [s. 1.]: IEA Bioenergy Task 40, $2016.68 \mathrm{p}$.

WOLF, A.; VIDLUND, A.; ANDERSSON, E. Energy-efficient pellet production in the forest industry - a study of obstacles and success factors. Biomass \&Bioenergy, Amsterdam, v. 30, n. 1. p. $38-45,2006$.

WU, M. R.; SCHOTT, D. L.; LODEWIJKS, G. Physical properties of solid biomass. Biomass \&Bioenergy, Amsterdam, v. 35, n. 5, p. 2093-2105, 2011.

ZWART, R.; BOERRIGER, H.; VAN DER DRIFT, A. The impact of biomass pre-treatment on the feasibility of overseas biomass conversion to Fischer-Tropsch products. Energy \& Fuels, Washington, v. 20, p. 2192-2197, 2006. 